\title{
SANGRAMENTO NASAL EM GESTANTES: RELATO DE CASO DE HEMANGIOMA CAPILAR LOBULAR NASAL
}

\section{ARTIGO ORIGINAL}

PASSOS, Fabio Manoel dos ${ }^{1}$

PASSOS, Fabio Manoel dos. Sangramento nasal em gestantes: Relato de caso de hemangioma capilar lobular nasal. Revista Científica Multidisciplinar Núcleo do Conhecimento. Ano 05, Ed. 12, Vol. 07, pp. 46-52. Dezembro de 2020. ISSN: 24480959, Link de acesso: https://www.nucleodoconhecimento.com.br/saude/sangramento-nasal

\section{RESUMO}

O sangramento nasal é tido como emergência médica dentro do campo da otorrinolaringologia. Isso se dá por intermédio de uma condição especifica, visto que se não tratada adequadamente, é capaz de produz morbidade aumentada e piorar as condições de vida diária, assim como maior tempo de afastamento das atividades laborais. Várias são suas causas. Outrossim, o presente trabalho tem como função mostrar um caso específico, e relativamente raro, de sangramento nasal provocado por um hemangioma capilar lobular localizado na fossa nasal, em uma gestante.

Palavras-chave: Rinologia, sangramento nasal em gestante, epistaxes.

\section{INTRODUÇÃO}

De acordo com Coutinho, Corte, Spratley, Rios e Santos (2016), "O hemangioma capilar lobular é uma neoformação vascular benigna relativamente frequente na cabeça e pescoço, sendo extremamente rara a sua localização no vestíbulo nasal.".

1 Residente em Otorrinolaringologia e Cirurgia Cérvico-Facial; Graduação em Medicina pela Universidade Federal do Paraná - UFPR. 
O sangramento nasal causa nos pacientes sofrimento, angústia e nervosismos, desde os de pequena monta quanto os de grandes sangramentos. Em geral, os sangramentos nasais se alocam na região anterior do septo nasal, local extremamente vascularizado devido ao plexo de Kiesselbach, entretanto, outras regiões, também, são afetadas, como: as aéreas arteriais que suprem o septo; e as demais cavidades nasais.

A hemangioma deve ser diagnosticada ao obter uma suspeita de obstração nasal, com dor no local ou deformidade fácil, sua suspeita deve ser atrelada à ocorrência de epistaxe intermitente. A hemangioma nasal é notada quando se obtém um aumento ao realizar a rinoscopia ou a fibroendoscopia nasal. Tal relação é constatada ao apresentar tumoração avermelhada, lisa e, geralmente, arredondada inserida no septo nasal ou nos cornetos. O diagnóstico é determinado através da arteriografia, da tomografia computadorizada e da ressonância magnética.

Devido a isso, a hemangioma é tida como emergência médica na otorrinolaringologia, e se faz necessária uma abordagem rápida e precisa, visando conter o sangramento. É importante salientar que em alguns casos o sangramento cessa espontaneamente, no entanto, há casos que necessitam de abordagens ou de cauterização química com ATA (ácido tricloroacético) 70\% ou cauterização elétrica em centro cirúrgico.

\section{RELATO DO CASO}

Paciente G. P. C. de 28 anos, sexo feminino, vem ao hospital em 21 de abril de 2019 com queixa de sangramento nasal recorrente em fossa nasal direita, intensificada nas últimas três semanas.

Atendida na unidade de Pronto Atendimento do Hospital Otorrino - hospital de referência em Otorrinolaringologia na cidade de Cuiabá/MT — apresentando epistaxe repetidamente há três semanas, seu caso evolui para uma massa nasal que obstruiu toda a sua fossa nasal direita há dois dias, como mostra a Figura 1. A paciente encontrava-se com 26 semanas de gestação. 
Figura 1- massa obstruindo totalmente a fossa nasal direita
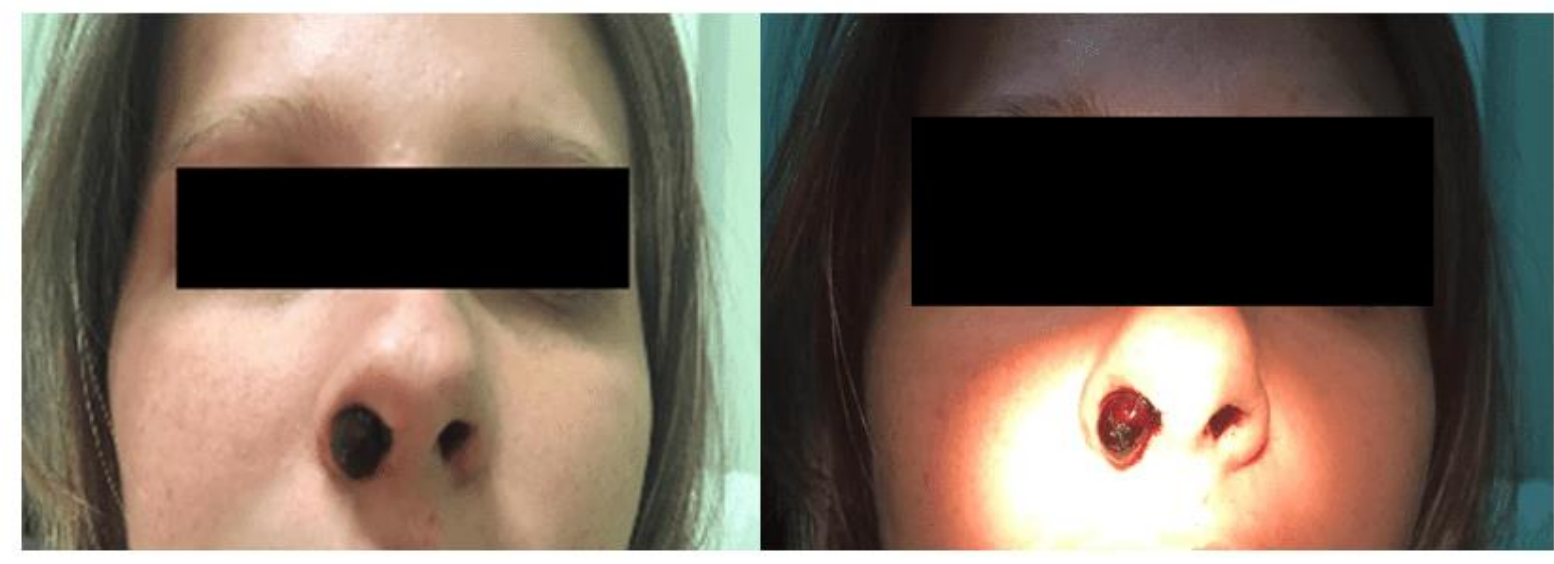

Fonte: compilação do autor.

Durante o exame físico, a paciente apresentava-se em bom estado geral: orientada em tempo e espaço; normocorada; hidratada; eupneica; e normotensa. Não apresentava alterações à orofaringoscopia e otoscopia. Alterações apenas à rinoscopia anterior, na qual se observava massa tumoral obstruindo totalmente a fossa nasal direita.

Diante da situação, realizou-se a estabilização clínica da paciente e solicitou-se o de exame complementar de videonasofibroscopia (VNF) flexível para que houvesse uma avaliação completa da lesão e origem do sangramento, posterior, podendo-se planejar o tratamento.

O exame de imagem (VNF) identificou lesão nodular que ocupava por completo a fossa nasal direita, sem sinais de comprometimento das estruturas nasais posteriores, sendo o local de inserção no septo nasal anterior.

Dessa forma, optou-se por tratamento cirúrgico, realizado no próprio centro cirúrgico, visto haver um maior cuidado anestésico para com o caso. Retirou-se a lesão e realizou-se a cauterização elétrica onde estava ocorrendo a inserção do pedículo da lesão no septo nasal, sem intercorrências. No retorno da paciente, a mesma se apresentava com boa evolução do quadro e sem sangramentos nasais após a 
realização do procedimento. Optou-se por acompanhar semestralmente a lesão, sempre realizando o exame de imagem (VNF).

\section{DISCUSSÃO}

A epistaxe, palavra de origem grega (epi= acima; stazein= gotejar) é o termo médico utilizado para designar aos sangramentos nasais. De acordo com o artigo "Tratamento da Epistaxe" de Balbani, Formigoni e Butugan (1999), a epistaxe é compreendida por ser uma alteração da hemostasia do nariz, ou seja, originária dentro da cavidade nasal, sua causa se dá por intermédio do comprometimento da integridade da mucosa. Foi realizado uma pesquisa e ficou estimado que tal condição está disposta em $60 \%$ das pessoas, ao longo da vida. É integrado pela literatura médica que apenas $6 \%$ desses sangramentos são casos que merecem um tratamento médico. Essa porcentagem é condicionada por meio de uma distribuição bimodal, em que se entende que a idade procedente para tal condição médica é aos 10 anos ou entre 45 e 65.

A maior ocorrência dos casos de epistaxe são: na região anteroinferior septal; no plexo de Kiesselbach; e/ou área de Little. A fisiopatologia da epistaxe, considerado pelo livro "Tratado de otorrinolaringologista", de Pignatari e Anselmo Lima (2018),

envolve alterações da fisiologia nasal, determinadas por estímulos extrínsecos ou intrínsecos (mecânicos, neurogênicos, alergênicos, físicos, químicos ou inflamatórios). Esses estímulos provocam modificações de volume sanguíneo, na função glandular local e integridade da mucosa, expondo, por consequência, a vasculatura e favorecendo a epistaxe. (2007, n.p.)

Se propõe, inicialmente, que o paciente acometido de epistaxe se aplique os algoritmos do tipo Advanced Trauma Life Support (ATLS), disposto, também, pela obra de Pignatari e Anselmo Lima, "proteção da sua via aérea e avaliação precisa com pronta estabilização de suas condições hemodinâmicas." (n.p.). É necessário que o otorrinolaringologista esteja devidamente paramentado e munido de instrumentos adequados e específicos para realizar o exame da cavidade nasal. Espera-se que o 
profissional disponha de boa iluminação (endoscópio, quando disponível) e aspirador para a remoção de coágulos.

Ao realizar o exame, o mesmo será feito por meio de anestesia tópica e com vasoconstritores, para que consiga uma boa avaliação da cavidade nasal, objetivando a precisa localização da origem do sangramento. No caso em discussão, os vasoconstritores não foram utilizados devido à paciente encontrar-se gestante.

O hemangioma capilar lobular da cavidade nasal é um tumor benigno, entretanto, sua ocorrência no septo nasal é rara. Os sintomas referentes à são: dor; sangramento nasal recorrente; e/ou obstrução unilateral. Atualmente, a literatura ainda não compreende a etiologia e os fatores predisponentes são pouco esclarecedores, contudo, na paciente fatores como, o trauma da mucosa, gravidez e os hormônios podem estar relacionados.

Desse modo, em geral, se descobre de forma incidental, o quadro de epistaxe e a obstrução nasal de rápida instalação. Habitualmente, os hemangiomas capilares lobulares são descritos como lesões de crescimento rápido, que atingem dimensões entre 1 a $2 \mathrm{~cm}$ em poucas semanas, relacionando com o presente caso, principalmente com a estimulação hormonal advinda da gravidez.

A isso, se infere a fundamental realização do exame histopatológico para o diagnóstico de hemangioma capilar lobular, já que consta com evidência de proliferação endotelial havendo espações vasculares proeminentes, capilares em padrão lobular, ulceração do epitélio e um pedículo composto por tecido fibrovascular.

De acordo com o artigo Hemangioma capilar lobular do vestíbulo nasal, uma casa rara da epistaxis, de Gil Coutinho; Filipa Corte; Jorge Spratley; Elisabete Rios; e Margarida Santos (2016, p.263),

a exérese cirúrgica com margens é geralmente suficiente para o sucesso do tratamento. Tendo em consideração as suas propriedades hemostáticas e uma menor recorrência, alguns autores preconizam a cauterização da base de implantação do hemangioma capilar lobular com eletrocoagulação, crioterapia ou laser. 
No caso exposto, a paciente foi internada para avaliação com exame de imagem (videonasofibroscopia) e abordagem em centro cirúrgico. Realizou-se a exérese da lesão e cauterização com eletrocoagulação com a paciente em anestesia geral. Obteve-se uma boa evolução durante o procedimento e pós-operatório, sem recidivas pós-operatória. Coletado o material para anatomopatológico e imuno-histoquímica (como mostrará a figura 2) (positivos para: CD 34 - células endoteliais; CD 31 - células endoteliais; ERG; Antígeno de proliferação celular ki 67, sendo este positivo em <2 $\%$ das células neoplásicas), na qual se chegou ao diagnóstico de Hemangioma Capilar Lobular de cavidade nasal.

Figura 2: quadro de Imunohistoquímica da lesão

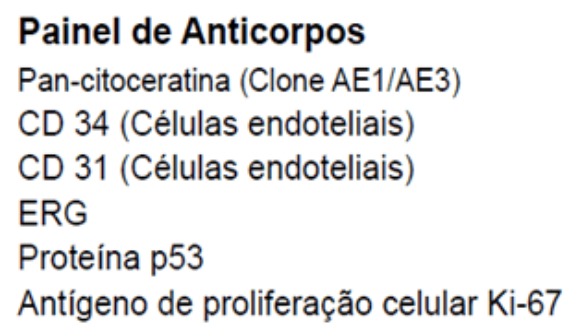

\author{
Resultado \\ Negativo \\ Positivo \\ Positivo \\ Positivo \\ Negativo \\ Positivo em $<2 \%$ das células neoplásicas
}

Diagnóstico: Neoplasia vascular com características morfológicas e imunoistoquímicas, com positividade para CD 31, CD 34 e ERG, em células endoteliais, que favorecem o diagnóstico de hemangioma capilar lobular, de cavidade nasal.

Fonte: compilação do autor.

\section{CONCLUSÃO}

O caso relatado ocorreu em unidade de Pronto Atendimento de um Hospital de referência em Otorrinolaringologia na cidade de Cuiabá/MT.

A paciente deu entrada como emergência otorrinolaringológica, pois apresentava sangramento nasal importante com obstrução unilateral direita. Trata-se de patologia de características benignas, mas devido ao crescimento rápido e possibilidade de sangramento nasal maciço, principalmente de se tratar de uma gestante, foi 
necessária uma abordagem rápida com excisão da lesão e acompanhamento de recorrências.

Até o momento da publicação deste trabalho não foram observadas recidivas do tumor nasal.

\section{REFERÊNCIAS}

COUTINHO, G.; CORTE, F.; SPRATLEY, J.; RIOS, E.; SANTOS, M. Hemangioma capilar lobular do vestíbulo nasal, uma causa rara de epistaxis. Revista Portuguesa De Otorrinolaringologia E Cirurgia De Cabeça E Pescoço. 2016. Disponível em: <https://www.journalsporl.com/index.php/sporl/article/view/645> Acesso: 25 nov. 2020.

FONSECA, Marconi T.; LACERD, Marcos A. C.; SILVA, Raquel T. F.; BARREIROS, Aureliano C. Hemangioma Nasal e Gravidez: relato de Caso e Revisão da Literatura. Arq. Fund. Otorrinolaringologista. 2001. Disponível em: <http://arquivosdeorl.org.br/additional/acervo_port.asp?id=152> Acesso: 25 nov. 2020

PIGNATARI, S. S. N; ANSELMO-LIMA, W. T. Tratado de otorrinolaringologia. Rio de Janeiro: Elsevier, 2018.

VALENTE, Pedro; PINTO, Isabel Gomes; PENÊDA, José Ferreira; GAMA, Rita; LARANGEIRO, João; CASTRO, Eugénia; CONDÉ, Artur. Hemangioma capilar lobular de septo nasal em dois pacientes jovens. Acta Otorrinolaringol. Gallega, 2018. Disponível em: <https://dialnet.unirioja.es/servlet/articulo?codigo=6906429> Acesso: 25 jul. 2020.

Enviado: Novembro, 2020.

Aprovado: Dezembro, 2020. 